\title{
CENOGRAFIAS E CINEGRAFIAS DO OLHAR E DA MEMÓRIA
} CENOGRAPHIES AND CINEGRAPHIES OF THE GAZE AND MEMORY CENOGRAFÍAS Y CINEGRAFÍAS DE LA MIRADA Y DE LA MEMORIA

\section{RESUMO:}

É nossa intenção, com base em Campo de trânsito, do escritor moçambicano João Paulo Borges Coelho, e em Virgem Margarida, de Licínio Azevedo, cineasta brasileiro radicado há anos em Moçambique, discutir de que forma os referidos romance e filme representam a ação opressora dos campos de reeducação em Moçambique e não só. O estado de exceção e a teatralidade do absurdo.

PALAVRAS-CHAVE: João Paulo Borges Coelho, Licínio Azevedo, campos de reeducação, teatro do absurdo, Moçambique.

\section{ABSTRACT:}

It is our intention, based on the novel Campo de trânsito, by Mozambican writer João Paulo Borges Coelho, and in the film Virgem Margarida, by Licínio Azevedo, Brazilian filmmaker who lives in Mozambique, to discuss how these literary and cinematographic texts represent the oppressive action of the reeducation camps in Mozambique and not only. The state of exception and the theatricality of the absurd.

KEYWORDS: João Paulo Borges Coelho, Licinio Azevedo, reeducation camps, theater

1 Professora Titular de Literaturas Africanas da Universidade Federal do Rio de Janeiro - UFRJ; Pesquisadora 1 do CNPq; Cientista do nosso Estado da FAPERJ; membro da Cátedra para Estudos Literários LusoAfro-Brasileiros Jorge de Sena; 2a Vice-Presidente da AFROLIC. E-mail: carmen.tindo@gmail.com

Este texto foi originalmente apresentado no evento sobre João Paulo Borges Coelho, realizado na Universidade de Lisboa em julho de 2017. 
of the absurd, Mozambique.

\section{RESUMEN:}

Es nuestra intención, basada en la novela Campo de trânsito, de el escritor mozambiqueño João Paulo Borges Coelho, y en la película Virgem Margarida, de Licínio Azevedo, cineasta brasileño arraigado durante años em Mozambique, discutir cómo estos textos literario y cinematográfico representan la acción opresiva de los campos de reeducación en Mozambique y no solamente. El estado de excepción y la teatralidad del absurdo.

PALABRAS-CLAVE: João Paulo Borges Coelho, Licínio Azevedo, campos de reeducación, teatro del absurdo, Mozambique.

Com base em Campo de trânsito, do escritor moçambicano João Paulo Borges Coelho, e em Virgem Margarida, de Licínio Azevedo, cineasta brasileiro radicado há anos em Moçambique, é nossa intenção investigar de que forma os referidos romance e filme representam a ação opressora dos campos de reeducação em Moçambique e não só.

Entre 1974 e o início da década de 1980, milhares de pessoas em Moçambique (...) foram forçadas a ir para campos de reeducação. A maior parte não voltou.

Os primeiros anos da história de Moçambique independente foram um período conturbado. Ainda antes da independência de Moçambique, o governo marxista da FRELIMO sentia a necessidade de eliminar os comportamentos e costumes associados ao colonialismo português e ao sistema capitalista; queria criar uma nova mentalidade e uma sociedade socialista. (SOUSA, 2013²)

Durante os anos 1980 e 1990, pesado silêncio pairou sobre a existência desses campos. Silêncio rompido pela arte duas décadas depois: primeiramente, pela literatura, em 2002, com o livro No reino dos abutres, de Ungulani Ba Ka Khosa, e com Campo de trânsito, de João Paulo Borges Coelho, em 2007; depois, com o cinema, com o filme Virgem Margarida, produzido em 2012.

Embora tanto o romance de Borges Coelho quanto o filme de Licínio tenham como cenários campos com prisioneiros forçados a viverem em estado de exceção ${ }^{3}$ - conforme observou Nazir Can em artigo sobre o livro de João Paulo -, as abordagens e as estratégias estéticas utilizadas em Campo de trânsito e Virgem Margarida são diferentes. Nossa análise procurará

\footnotetext{
2 SOUSA, 2013. Disponível em: http://www.dw.com/pt-002/as-feridas-abertas-pelo-processodereeduca\%C3\%A7\%C3\%A3o-em-mo\%C3\%A7ambique/a-16948901

3 CAN, 2009, p. 105-117.
} 
apontar essas diferenças e algumas semelhanças.

\section{Campo de trânsito: cenografias do absurdo}

Numa esquina qualquer, o sentimento do absurdo pode bater no rosto de um homem qualquer. Tal como é em sua nudez desoladora, em sua luz sem brilho, esse sentimento é inapreensivel. Mas essa dificuldade merece reflexão. ${ }^{4}$

Albert Camus

A narrativa de Campo de trânsito se abre com três pancadas na porta do apartamento do protagonista, J. Mungau. O som surdo se repete até ele vir atender. As pancadas funcionam como as "batidas de Molière" que, nos teatros, em geral, servem para pedir silêncio ao público, avisando que a peça vai começar. Em espetáculos teatrais clássicos, é o contra-regra quem bate o cajado no palco, marcando a entrada e a saída das personagens, sendo o responsável pela mudança dos cenários. No romance de João Paulo, Bexigoso, personagem que veio deter Mungau às cinco da madrugada, pode ser considerado uma espécie de contra-regra, pois é quem faz soarem as mencionadas batidas que acordam o protagonista e dá a este ordem de prisão, levando-o, sem explicações, para uma cela do Comando Central na cidade.

Enquanto, no filme Virgem Margarida, os espaços são bem delimitados — a capital moçambicana, Maputo, e os campos de reeducação no Niassa, ao norte de Moçambique —, no romance Campo de trânsito, há uma indistinção geográfica: os campos de trânsito podem estar no território moçambicano, mas também em outros lugares e países. Tal imprecisão topográfica foi registrada por Nazir Can em seus estudos sobre João Paulo ${ }^{4}$.

É instigante a posição do narrador que assume um ponto de vista heterodiegético, demonstrando onisciência em relação ao narrado, porém, por vezes, adentrando os pensamentos das personagens, o que acarreta a diminuição da distância própria de narrações em terceira pessoa. Penetrando no fluxo mental do protagonista, o narrador acompanha-lhe as dúvidas, digressões, medos, por meio de um narrar lento, arrastado, que expressa os sentimentos de Mungau diante do sem sentido da vida, naquele campo.

O escuro, as sombras da noite tingem o discurso enunciador, as descrições, não só da cena inicial, mas de outros cenários e paisagens. Há um clima de suspense, de desnorteamento, pois J. Mungau e os demais presos desconhecem as razões de suas detenções. Uma frase do protagonista perpassa o início do romance: “De que me acusam?” Tal interrogação se intercala ao narrar e às detalhadas descrições do narrador. $\mathrm{O}$ enredo se tece em atmosfera lúgubre de mistério, angústia, incerteza. A palavra escuro e vocábulos do mesmo campo semântico atravessam a

\footnotetext{
4 CAN, Nazir Ahmed. Discurso e poder nos romances de João Paulo Borges Coelho. Maputo: Alcance, 2014.
} 
narrativa. As sombras metaforizam as fantasmagorias de uma outra "grande noite"(MBEMBE, 2014b) que persiste e da qual Moçambique e outros países não conseguiram sair.

São evidentes as características do teatro do absurdo no romance de João Paulo. Na peça $O$ rinoceronte, de Ionesco (1976), a cidadezinha-cenário é uma qualquer de um país imaginário, funcionando como metafórico espaço de opressão para todos. Em Campo de trânsito, a cidade em que morava Mungau e o campo de trânsito também não são nomeados e alegorizam a ambiência opressiva que se abate sobre as personagens. Os dois textos lançam um olhar de estranheza em relação a regimes totalitários; em ambos, o onírico exprime os paradoxos gerados pelas arbitrariedades e abusos de poder.

“Teatro do absurdo”, denominação criada em 1961 por Martin Esslin, diz respeito a espetáculos, cujos enredos têm a ilogicidade como traço recorrente, assim como o nonsense provocado por certas situações advindas de deformidades da realidade social.

(...) num universo repentinamente privado de ilusões e de luz, o homem se sente um estranho. Seu exílio é irremediável, porque foi privado de lembrança de uma pátria perdida tanto quanto da esperança de uma terra prometida futura. Esse divórcio entre o homem e sua vida, entre ator e seu cenário, em verdade, constitui o sentimento de absurdo. (CAMUS. Apud: ESSLIM, 1968, p. 19)

Mungau é afetado por um sentimento de estranheza. Envolto nas penumbras de uma teatralidade absurda, é preso e transportado, inicialmente, para uma cela minúscula na cadeia da cidade. Como forma de reagir, em meio à resignação e ao espanto, inventa o teatro da imaginação para manter alguma dignidade. A cela se torna o palco (COELHO, 2007, p. 20-25), a plateia se encontra na escuridão, o trapezista se revela metáfora do equilíbrio que procura manter, até que desperta com a queda do equilibrista. É noite; o vazio e a solidão o invadem. Na plateia, avista Bexigoso, personagem que - descobre depois - é o responsável por levar grupos de detidos para os campos de reeducação, campos, na verdade, de trânsito para a morte.

Após dias presos no Comando Central, Mungau e outros detidos são levados por caminhões a um aeroporto, onde são forçados a entrarem num avião que voa para longe do urbano. Ali, outros caminhões os esperam para os encaminharem ao campo de trânsito, localizado em território bem distante, cercado por florestas densas, de um verde-escuro ameaçador, cheias de animais ferozes.

O narrador descreve, minuciosamente, as paisagens que se afiguram como cenários dantescos. Ao chegarem ao campo, o detalhamento descritivo se exacerba; são muitas as repetições e redundâncias discursivas - outra característica marcante do teatro do absurdo. O olhar do narrador vai deambulando pelo espaço do campo, acompanhando o olhar de Mungau. Como um olho-câmera, vai, cinematograficamente, captando paisagens, outros prisioneiros, as casas, certos objetos. Efetua cortes, passa de um plano a outro. Cria cenografias que representam o 
absurdo da perda de liberdade.

Martin Esslin ${ }^{5}$ (1970, p. 4-9), referindo-se à peça The Brig, de Kenneth Brown, comenta que esta denuncia o modo como tratam os prisioneiros num campo de detenção da marinha americana, regido por rígido sistema disciplinar: "No chão há riscos brancos. A cada momento um prisioneiro deseja cruzar a linha branca e precisa pedir permissão a um guarda (ESSLIM, 1970, p. 5)." Procedimento semelhante encontramos em Campo de trânsito:

Bexigoso explica o procedimento sempre que uma leva de presos chega ao Campo. Ao seu lado, um guarda enuncia em voz alta o nome de cada um. Assim que é nomeado, o detido dá um passo em frente e atravessa o risco para o outro lado. Ao mesmo tempo que o faz, o Bexigoso, também em voz alta - e depois de consultar suas listas -, atribui-lhe um número. (...) (COELHO, 2007, p. 42).

J. Mungau, logo que detido, se perguntava constantemente por que motivos o haviam prendido; depois, foi-se adaptando, procurando sobreviver e não mais se questionou. Ao entrar em contato com o Diretor do Campo, foi percebendo as negociações que eram feitas, simbolicamente, para a sobrevivência ali. São exemplos desses jogos de poder, tramados com o Diretor, a aquisição da colher para se alimentar melhor; da faca para a defesa pessoal; do lápis e do caderno para a redação do encomendado relatório sobre os campos vizinhos, o Antigo e o Novo, cujos propósitos eram opostos: a recuperação da tradição e a criação de novas tecnologias. Mungau compreendeu que, para viver ali, tinha de se adaptar.

Esslin e Ionesco (1965), ao teorizarem sobre o teatro do absurdo, apontam como traços recorrentes: a violência; a opressão; situações tragicômicas; personagens repetitivas, monótonas, animalizadas, reféns de suas decepções e desesperanças.

Em Campo de trânsito, é caricatural e grotesca a descrição das personagens, havendo sempre uma associação destas com animais. Bexigoso ostenta pescoço taurino; o Diretor tem mãos de aranha sempre a manipular o poder; a Mulher do Professor possui somente dois dedos na mão que formam uma pinça de inseto; a filha do Chefe da Aldeia é denominada Garça Desengonçada. As deformidades alegorizam conflitos e desarmonias sociais, a perda da condição humana.

Ionesco (2006) chama atenção para uma das propostas do teatro do absurdo: "“fazer um teatro de violência': violentamente cômico, violentamente dramático. Exagerando os traços, ele caricatura a humanidade sem, contudo, traí-la." (MINOIS, 2003, p. 586). Tal violência, oscilando do trágico ao cômico, gera um riso nihilista e amargo, que o discurso enunciador vai provocando nos leitores. Outra característica do teatro do absurdo presente no romance é o 
enredo monótono, cíclico, com personagens angustiadas apresentadas aos pares. Por exemplo: são amigos o Chefe da Aldeia e o Vendedor de Chá (COELHO, 2007, p. 166); o Professor e o prisioneiro 13.2. São inimigos o Diretor e o Chefe da Aldeia (idem, p. 118); o Professor e o Diretor. Este só valoriza o presente (idem, p. 130); já o Chefe da Aldeia defende o passado e as tradições (idem, p. 128), enquanto o Professor sonha com o futuro (idem, p. 131 e p. 171).

Em Campo de trânsito, as personagens, em duplas antitéticas, travam, o tempo todo, exacerbados jogos de (e pelo) poder. Estes acabam levando a um desfecho fúnebre - o assassinato do Diretor. O mistério dessa morte permanece: quem o teria apunhalado? Teria sido J. Mungau, o dono da lâmina fatal? A Mulher do Professor (a quem Mungau emprestara a faca), com quem o Diretor se relacionava erótica e violentamente? O Professor, por ciúmes da esposa? O prisioneiro 13.2, amigo inseparável do Professor? O Chefe da Aldeia que competia com o Diretor?

A narrativa termina em aberto e, ciclicamente, ouvem-se "três pancadas surdas na porta" (COELHO, 2007, p. 197) que anunciam o fim do espetáculo: a Mulher do Professor arranca a faca do peito do Diretor, devolve-a a Mungau, cospe no cadáver. A figura onírica do equilibrista ressurge à janela. Mungau é transferido para a cidade pelo Bexigoso que ordena:

Prepara-te, diz com voz entaramelada. Está tudo pronto, vamos partir. Vamos partir para onde?, pergunta Mungau.

Não te esqueça do teu estatuto de prisioneiro. Não te cabe fazer perguntas!, diz severamente o Bexigoso, antes de soltar uma gargalhada. (COELHO, 2007, p. 208)

O protagonista tentara obter respostas às suas dúvidas, junto ao Vendedor de Chá. Mas este apenas vendia chá de cogumelos negros com efeito alucinógeno e falava por fábulas, emitindo mensagens cifradas, com palavras cheias de aliterações começadas com o mesmo fonema. Por exemplo: "rotineiros relatórios, ratoeiras, relacionamentos rivais, relevâncias, reminiscências, reviravoltas, regresso (COELHO, 2007, p. 198 e p. 199; grifos nossos). Assim, o enigma permanece indecifrado. A narrativa finda com o vazio, a solidão, o nonsense a expressarem o absurdo da existência daqueles campos.

\section{Virgem Margarida: a memória sombria dos campos de reeducação em Moçambique}

Mesmo que o Estado pós-colonial se veja como independente, ele ainda sofre de todas as cicatrizes coloniais em sua psique coletiva. A arte cinematográfica tem o dever de desmascarar a descolonização parcial da maioria da África (...). A descolonização não pode ser [apenas] parcial: ela deve ser total para todos os setores da população e em todos os níveis.(THIONG'O, 2007, p. 31)

O filme de Licínio Azevedo se abre com a imagem de uma poça de lama, em meio a uma 
rua de barro da capital moçambicana. Um caminhão, cheio de pessoas na carroceria, celebra a independência, ostentando uma faixa com o slogan: A LUTA CONTINUA.

Soldados da FRELIMO percorrem a Rua Araújo, no centro de Maputo, e prendem prostitutas que ali circulavam à noite. Estas, sem entenderem, são levadas à força para locais onde seriam cadastradas para, a seguir, serem enviadas a campos de reeducação no norte do país. Biografias interrompidas. Assombramento. Degradação e exclusão. Pessoas exiladas dentro de Moçambique, sem compreenderem a razão, assistem à imposição de normas que passam a reger seus corpos e pensamentos.

Virgem Margarida focaliza a "Operação Limpeza" realizada pelo primeiro governo da FRELIMO, cujos objetivos eram livrar a nação de vícios antigos, "lavar a cabeça de ideias colonialistas." A poça de lama no início do filme metaforiza a "sujeira" que, segundo a FRELIMO, precisava ser removida do país recém-criado.

Segundo o antropólogo brasileiro Omar Ribeiro Thomaz, logo após a independência moçambicana, havia a ideia da construção do "Homem Novo," cujos pensamentos e condutas deveriam seguir os princípios ideológicos do marxismo-leninismo. Para os campos de reeducação iriam todos aqueles que, de uma forma ou de
outra, traziam consigo ou em si elementos da velha ordem que se desejava eli-
minar - régulos (autoridades tradicionais), feiticeiros, "comprometidos" (in-
divíduos sobre quem pesasse alguma suspeita de algum tipo de compromisso
com a velha ordem colonial), prostitutas; para os campos de trabalho, iriam
todos os que deveriam passar por uma ressocialização marcada pelo trabalho
em grandes campos de cultivo (machambas): sabotadores, inimigos, vadios.
(THOMAZ, 2008, p.180)

O plano era criar também a "Mulher Nova," aquela que deveria ser a esposa prendada do lar, mãe exemplar, descrente de qualquer religião. Para isso, as prostitutas das cidades necessitavam ser reeducadas em zonas rurais, afastadas do sexo e dos "pecados da carne.” Licínio Azevedo, cinematograficamente, aborda, justamente, essa "operação limpeza" que recolheu muitas prostitutas e as levou, à revelia, para campos de reeducação, na distante província do Niassa. Dentre as mulheres recolhidas, foi, por engano, Margarida, moça de aldeia, que tinha ido à cidade para comprar seu enxoval.

No campo, Camarada-Comandante Maria João era quem coordenava as mulheres ali aprisionadas, obrigando-as a trabalhar nas machambas, a construir palhotas, a fazer os serviços domésticos: cozinhar, lavar, varrer, etc. Maria João se portava como se fosse um homem, um soldado da FRELIMO. Tinha por princípios: a disciplina, a moral, a hierarquia, a ideologia do Partido Revolucionário. Dava ordem unida às reeducandas e castigava severamente as que desobedeciam aos seus comandos. Aplicava tortura nas que se mostravam rebeldes, o que reduplicava a "razão sacrificial” (MBEMBE, 2014a, p. 184) exercida pelo colonialismo, cuja prá- 
tica assentava no mando, na violência, no castigo, na dor, na morte impostos aos colonizados, "ferindo constantemente a humanidade dos submissos, multiplicando os golpes no seu corpo e atacando seu cérebro com o intuito de criar lesões" (MBEMBE, 2014a, p. 188).

Achille Mbembe, no livro Crítica da razão negra, aponta para "o paradoxo do comando" (MBEMBE, 2014a, p. 187), explicando que este, ao mesmo tempo que "tratava, [também] magoava" (idem, ibidem). Os colonizadores consideravam os colonizados selvagens; outorgavamse, então, o direito de tratar deles para que se tornassem civilizados e, para tal, os castigavam.

Nos campos de reeducação moçambicanos, paradoxo semelhante é encontrado, pois os comandantes julgavam que cabia a eles o ensinamento da boa conduta aos reeducandos e, se estes não lhes correspondessem, impingiam-lhes torturas.

No filme, as prostitutas apanhavam, eram colocadas dentro de um latão com água fria até o pescoço, sofriam racionamentos de comida, eram obrigadas a correr de braços abertos como um avião, tinham de se arrastar no chão como bichos rastejantes, eram enterradas e ficavam apenas com a cabeça descoberta. Os castigos eram atrozes e inumanos; chegavam até a causar mortes. Fanon, em seu livro Em defesa da revolução africana, adverte: "o colonialismo não se entende sem a possibilidade de torturar, de violar, de matar" (FANON, 1980, p.73).

As violências, praticadas nos campos de reeducação moçambicanos, têm, assim, suas origens explicadas no interior do sistema colonial. Mbembe (2014a, p. 201) observa que o colonialismo desenvolveu com a África uma exploração a partir dos desejos dos colonizados. Citando Fanon, lembra que "o racismo colonial possuía uma inquietação sexual” (MBEMBE, 2014a, p. 194). Às mulheres negras era atribuída, preconceituosamente, uma sexualidade "pecaminosa," capaz de atrair e seduzir; aos homens negros, era imputada uma potência sexual maior que a dos brancos. Tais concepções exóticas e estereotipadas introjetaram-se também no imaginário de alguns colonizados, levando a que herdassem atitudes reacionárias e autoritárias do machismo colonial. Foi o que ocorreu, no filme, em relação à Margarida, cuja virgindade foi comprovada pelas reeducandas. Estando a jovem no campo por engano, suas companheiras prostitutas solicitaram à Comandante Maria João que o erro fosse corrigido. Logo a seguir, chegou ao acampamento o Comandante Felisberto, cujo mando era superior ao da Camarada Maria João. Ficou então resolvido que ele, quando voltasse à cidade, levaria a moça virgem para entregá-la à família. Na viagem, porém, ele violentou Margarida. Esta, aos prantos, conseguiu fugir. Voltou ao campo e as companheiras entenderam o que lhe acontecera. Houve uma comoção geral e a Camarada Maria João, indignada com o estupro de Margarida, reconheceu que o Comandante fora um reacionário tão ou mais machista que os colonialistas, cujos inúmeros abusos às negras faziam destas meros objetos de prazer sexual. A comandante, por isso, libertou as mulheres do campo.

A narrativa fílmica termina em aberto. As mulheres vão seguindo pelas estradas em ale- 
gria desmedida. A câmera mostra Margarida guardando na bolsa um fruto venenoso. O espectador se pergunta: as mulheres chegariam vivas à capital ou seriam comidas pelos leões que cercavam o campo? Por que Margarida colhera aquele fruto mortífero? Ela o comeria, se o noivo não a aceitasse? Tais questões ficam em suspenso.

Os campos de reeducação, ao quererem formar o "Homem Novo," a "Mulher Nova," criaram um outro tipo de autoritarismo do olhar, cuja ação controladora moldou várias vidas a partir do ideário da FRELIMO, partido que subiu ao poder com a independência de Moçambique. Isso gerou paradoxos. Se "a escravidão foi a remoção do direito de olhar" (MIRZOEFF, 2011, p. 481), os trabalhos forçados e as torturas em relação às reeducandas fizeram destas verdadeiras escravas que também perderam não só o direito de olhar, mas ainda o direito de agir, de pensar, de se manifestar. Colonialidades internalizadas voltam a assombrar, liberando fantasmas coloniais que ficaram introjetados no imaginário social moçambicano. Paulo Medeiros, no artigo "Pós-colonialidade espectral," denuncia a presença de uma "pós-colonialidade assombrada pelo colonialismo" (MEDEIROS, 2012, pp. 129-142).

De acordo com Marc Ferro, historiador que estuda as relações entre História e Cinema, "a câmera desvela o segredo, apresenta o avesso da sociedade, seus lapsos" (FERRO, 1992, p. 86). Funciona, portanto, como um olho crítico que apreende lacunas e revela contradições da história.

\section{Concluindo: amarrando pontas, tecendo reflexões...}

Tanto em Campo de trânsito como em Virgem Margarida, o olhar crítico da enunciação atesta a persistência de sombras e fantasmas coloniais. O filme põe em questão a dicção monológica do projeto de nação que excluía tudo que era divergente, ao idealizar o "Homem Novo" para o Moçambique independente. O romance, sem delimitar a geografia de seu cenário, questiona amplamente qualquer sistema autoritário. Perpassado por características do teatro do absurdo, o livro de João Paulo opera com cenografias oníricas, cujas imagens alegóricas expressam o nonsense dos regimes de exceção.

Segundo Joel Zito Araújo (2015), o filme de Licínio consiste em uma cinegrafia de reflexão crítica, cuja linguagem é mais direta em relação à realidade social. Para o mencionado crítico de cinema, a cinematografia dos países africanos de língua portuguesa tem como modelo o cinema neorrealista italiano e o brasileiro, assim como os "docudramas", mescla de documentário e ficção, em que os cenários são locais reais e os enredos são dramas verídicos vivenciados pelo povo que sofreu com as guerras.

Embora Campo de trânsito adote um narrar alegórico e surreal, e Virgem Margarida, um discurso realista, o olho-câmera da narrativa de Licínio, bem como o método observacional do 
olhar do narrador de João Paulo acabam por se tangenciar, pois ambos, denunciando clichês e ordens absurdas impostas, efetuam uma revisitação crítica da história. Nesse sentido, a narrativa fílmica e a romanesca se socorrem de um "olhar descolonial," na medida em que põem a nu certos espectros do passado colonial que ainda ensombram e assombram a história. Evidenciando paradoxos e contradições, o romance e o filme questionam o vazio, a fragilidade e a perda da liberdade que causa(ra)m danos irreparáveis aos seres humanos em geral.

\section{REFERÊNCIAS:}

ANDRADE, Welington. O Teatro e as Metamorfoses do Olhar. Revista CULT, edição 189. SP, 2014. Disponível em: <http://revistacult.uol.com.br/home/2014/05/o-teatro-e-as-metamorfoses-do-olhar/>. Acesso em 10 jan. 2017.

ALVARENGA, Nilson Assunção e LIMA, Marília Xavier de. O Afeto em Deleuze: o Regime Cristalino e o Processo Afetivo da Imagem-Tempo no Cinema. Portal Revistas UCB. Disponível em: <http://portalrevistas.ucb.br/index.php/esf/article/viewFile/2911/2158>. Acesso: $15 / 2 / 2015$.

ANZIEU, Didier. Le moi-peau. Paris: Dunod, 1985, p.31.

ARAÚJO, Joel Zito. O que é o Cinema Africano?. In: África, cinema: um olhar contemporâneo. Publicação da Mostra de Cinema da Caixa Cultural. Rio de Janeiro: Caixa Econômica Cultural, 30 jun. a 12 jul. 2015.

ARENAS, Fernando. Retratos de Moçambique pós-Guerra Civil: a filmografia de Licínio de Azevedo. In: BAMBA, Mahomed; MELEIRO, Alessandra (orgs.). Filmes da África e da diáspora: objetos de discursos. Salvador: EDUFBA, 2012. p. 75-98.

AUMONT, Jacques; MARIE, Michel. Dicionário teórico e crítico de cinema. Tradução de Eloisa Araújo Ribeiro. Campinas, SP: Papirus, 2003.

AZEVEDO, Licínio (Dir.). Virgem Margarida. Maputo; Lisboa; Paris; Luanda: Ébano Produções; Ukbar Filmes; JBA Production; DREADLOOCKS, 2012. Filme de 90 min. Disponível em: <https://www.youtube.com/watch?v=DZlwSOXuyP8>. Acesso em 25 jan. 2017.

BAMBA, Mahomed. O(s) cinema(s) africano(s): no singular e no plural. In: BAPTISTA, Mauro; MASCARELLO, Fernando. Cinema mundial contemporâneo. Campinas, SP: Papirus, 2012. p. 215-231. 
BOUGHEDIR, Ferid. O cinema africano e a ideologia: tendências e evolução. In: MELEIRO, Alessandra (Org.). Cinema no mundo: indústria, política e mercado-África. São Paulo: Escrituras, 2007. p. 37-56.

CABAÇO, José Luís. Percurso do cinema moçambicano. In: ARAÚJO, Guido (org.). Trocas culturais afro-luso-brasileiras. Salvador: Contraste, 2005. p. 12-19.

CAMUS, Albert. O mito de Sísifo: ensaio sobre o absurdo. Trad. de Ari Roitmane PaulinaWatch. Rio de Janeiro: Editora Record, 2004.

CAN, Nazir Ahmed. Para além da História: Campo de trânsito de João Paulo Borges Coelho. In: Via Atlântica, n. 16, p. 105-117. São Paulo: USP, 2009. Disponível em: < http://www.revistas.usp.br/viaatlantica/article/view/50466>. Acesso em 19 jan. 2017.

CAN, Nazir Ahmed. Discurso e poder nos romances de João Paulo Borges Coelho. Maputo: Alcance, 2014.

CARVALHO, Wellington Marçal. Viagem e Exílio em Campo de Trânsito de João Paulo Borges Coelho. In: Cadernos CESPUC. N. 18. Belo Horizonte: PUCMG, 2009. p.43-51. Disponível em: <http://periodicos.pucminas.br/index.php/cadernoscespuc/article/view/2426>. Acesso em 15 dez. 2016.

COELHO, João Paulo Borges. Campo de trânsito. Lisboa: Caminho, 2007.

DELEUZE, Gilles. Espinosa. Filosofia prática. Trad. Daniel Lins e Fabien Pascal Lins. São Paulo: Escuta, 2002.

DELEUZE, Gilles. Cinema 1: a imagem-movimento. Trad. Stella Senra. São Paulo: Brasiliense, 1985.

DELEUZE, Gilles. Cinema 2: a imagem-tempo. Trad. Eloisa de Araujo Ribeiro. São Paulo: Brasiliense, 2009.

ESSLIN, Martin. O teatro do absurdo. Trad. de Bárbara Heliodora. Rio de Janeiro: Zahar Editores, 1968.

ESSLIN, Martin. “A Violência no Teatro". Cadernos de Teatro. N. 47. Rio de Janeiro: publicação d'O Tablado, out.- nov.-dez. de 1970. p. 5-9. Disponível em: <http://otablado.com.br/ wp-content/uploads/notebooks-theater/457e4792f62ae8de0d198671af4e436b.PDF>. Acesso: 
18 jan 2017.

FANON, Frantz. Os condenados da terra. Trad. de Enilce Alberfaria Rocha, Lucy Magalhães. Juiz de Fora: Ed. UFJF, 2005.

FANON, Franz. Em defesa da revolução africana. Trad. Isabel Pascoal. Lisboa: Sá da Costa, 1980.

FERRO, Marc. Cinema e história. Trad. Flavia Nascimento. São Paulo: Paz e Terra, 1992.

FOUCAULT, Michel. Vigiar e punir: nascimento da prisão. Trad.: Raquel Ramalhete. Petrópolis: Vozes, 1987.

HINOJOSA, Fedra R.. Pas de Deux: a questão dos pares no teatro do absurdo. In: Palimpsesto. Programa Pós-Graduação em Letras UERJ. N.10. Ano 9. RJ: UERJ, 2010. p. 1-11. Em: <http:// www.pgletras.uerj.br/palimpsesto/num10/dossie/palimpsesto10_dossie08.pdf $>$. Acesso em 28 dez. 2016.

IONESCO, Eugène. O rinoceronte. Trad. Luís de Lima. São Paulo: Abril Cultural, 1976.

IONESCO, Eugène. A cantora careca. Trad. de Maria Lúcia Pereira. Campinas: Papirus, 1993.

IONESCO, Eugène. La tragédie du langage. In: Notes et contre-notes. Paris: Gallimard, 2006.

IONESCO, Eugène. Notas y contra-notas: estudios sobre el teatro. Trad. de Jaime Melendres. Buenos Aires: Losada, 1965.

MBEMBE, Achille. Crítica da razão negra. Trad. Marta Lança. Lisboa: Antígona, 2014a.

MBEMBE, Achille. Sair da grande noite: ensaios sobre a África descolonizada. Trad. Narrativa Traçada. Revisão de Sílvia Neto. Lisboa; Luanda: Edições Pedagogo; Edições Mulemba, 2014b.

MEDEIROS, Paulo. Spectral postcoloniality: lusophone postcolonial film and the imaginary of the nation. In: Postcolonial Cinema Studies. PONZANESI, Sandra e WALLER, Margueritte. London; New York: Routledge, 2012. pp. 129-142.

MIGNOLO, Walter. Desobediência epistêmica: a opção descolonial e o significado de identidade em política. Cadernos de Letras da UFF. Dossiê Literatura, língua e identidade, $\mathrm{n}^{\mathrm{o}} 34$, p. 287-324. Niterói: UFF, 2008. 
MIGNOLO, Walter. Histórias locais/projetos globais: colonialidade, saberes subalternos e pensamento liminar. Trad. de Solange Ribeiro de Oliveira. Belo Horizonte: Editora UFMG, 2003.

MINOIS, Georges. História do riso e do escárnio. Trad. de Maria Elena O. Ortiz Assumpção. São Paulo: UNESP, 2003.

MIRZOEFF, Nicholas. O Direito de Olhar. Critical Inquiry. Publicação de University of Chicago Press. Vol. 37, n. 3. Primavera de 2011. pp. 473-496.

MOGRABI, Gabriel José Corrêa e REIS, Célia Maria Domingues da Rocha (Org.). Cinema, literatura e filosofia: interfaces semióticas. Rio de Janeiro: 7 Letras, 2013.

NOVAES, Adauto et alii (Org.). O olhar. São Paulo: Companhia das Letras, 1988.

SOUSA, Glória. As Feridas Abertas pelo Processo de Reeducação em Moçambique. In: DW. Notícias. Publicação na internet em 31/08/2013. Disponível em:< http://www.dw.com/pt002/as-feridas-abertas-pelo-processo-dereeduca \%C3\%A7\%C3\%A3o-em-mo\%C3\%A 7ambique/a-16948901>. Acesso em 30 out. 2016.

SPINOZA, Benedictus. Ética. Trad. e notas de Tomaz Tadeu. Belo Horizonte: Autêntica, 2009.

THIONG'O, Ngugi Wa. A descolonização da mente é um pré-requisito para a prática criativa do cinema africano? In: MELEIRO, Alessandra (org.). Cinema no mundo: indústria, política e mercado-África. São Paulo: Escrituras, 2007. p. 25-32.

THOMAZ, Omar Ribeiro. 'Escravos sem dono': a experiência social dos campos de trabalho em Moçambique no período socialista. In: Revista de Antropologia. Vol. 51, no 1. São Paulo, USP, 2008, p. 177-214. 